\title{
ANTROPOLOGÍA LOS NIÑOS DE LA CALLE, ESE ICEBERG QUE NO QUEREMOS VER. UNA EXPERIENCIA DE COSTA RICA
}

\author{
Nora AGNes Villalobos \\ Doctora en Filosofia de Enfermería. Escuela de Enfermería
}

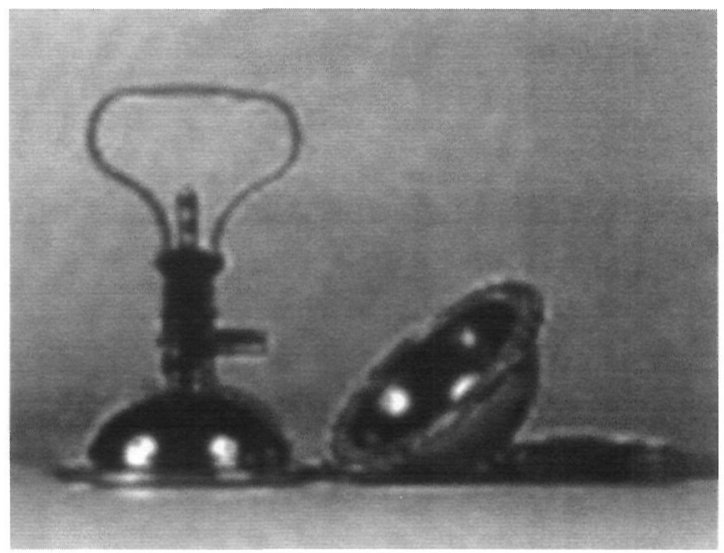

\section{RESUMEN}

Existen varios artículos que se refieren a las características de los niños (as) y adolescentes de/o en la calle en Costa Rica y en otros lugares de Centro y Sur América. También hay esfuerzos de muchas organizaciones para dar una solución a este problema. Hay instituciones en el país que los atienden, algunas herméticas que no permiten la realización de investigación por considerar que deben cuidar la "ïntegridad emocional" de los niños (as). El objetivo principal fue identificar las condiciones de vida de los niños (as) y adolescentes de / o en la calle y la experiencia de salud. Para ello se utilizó el incidente crítico y las notas de campo sobre su estilo de vida y el cuidado de su salud. La obtención de los resultados fue un tanto difícil por la desconfianza y hermetismo de los jóvenes con la presencia de extraños cerca de sus actividades en las brigadas, albergue y en la cancha de fútbol. Diversidad de ambientes y población flotante que impide una relación continua, permisiva y eficaz Se identificó que sin la socialización de una familia, sin una definición clara o concreta sobre salud, calidad de vida, libertad de decidir su cuidado de salud, sin un concepto claro de persona, tienen sin embargo una identidad propia, una forma de defender sus derechos, de tener salud, calidad de vida.

\section{THE CHILDREN OF THE STREET, THAT ICEBERG WHO WE DONT WANT TO SEE. A EXPERIENCE IN COSTA RICA}

\section{SUMMARY}

This work describes the life of the adolescent children who live in the street in Costa Rica and other places of Center and South America. The primary objetive was to identify the conditions of life of the children of the street and their experi experience of health. For it it was used the critical incident and notes of field on his style of life and the care of his health. Between the conclusions it is appraised that the children of the street have an own identity, a form to defend his rights, to have health, quality of life. 


\section{INTRODUCCIÓN}

La descripción de la experiencia que voy a relatar la presento de una manera personal porque es el contacto inicial con un grupo de la población, los niños (as) de la calle. Parto de una idea preconcebida cultural, social, ética de la experiencia de salud de los niños (as) y digo "preconcebida" porque inicié el trabajo con miedo a ser agredida física o emocionalmente. En Costa Rica son tratados de "chapulines" porque caminan en grupo asaltando (como la plaga de las plantaciones de cualquier tipo de granos), con armas punzocortantes en paradas de buses, mercados, parques. La población los evade por miedo, son el iceberg que no queremos ver.

¿Qué es un iceberg? "Masa de hielo flotante que procede de un glaciar" (GARCÍA- PELAYO y GROSS, 1976). Quiénes son los niños de la calle? Esa masa de personas flotantes que proceden de un mundo de injusticia social.

Según Blitzer (1993, p 60) el niño se define como un ser en formación, inmaduro, vulnerable, pasivo como un continente vacío que la sociedad llena con reglas, valores y conocimientos. No son sujeto de análisis porque su papel principal es crecer, educarse, internalizar normas y cultura y por sobre todo, convertirse en adultos. No hay forma satisfactoria de explicar o siquiera de percibir como los niños que trabajan a edades muy tempranas desarrollan ciertas habilidades y carecen de otras estipuladas en las escalas de desarrollo infantil.

Si comenzamos por explicar la injusticia social a la que nos referimos tendríamos para completar páginas y páginas de discursos de qué?, cómo?, cuándo?, del por qué? y no encontraríamos al igual que el iceberg, dónde anclar como puerto seguro. Tampoco es mi área de dominio, por eso solo puedo referirme a lo que sucede como un expectador más. No con un espíritu pesimista pero si realista de que la solución no está en mis manos. Hay algo de lo que se puede hablar y es de mi vivencia de unos meses con ese grupo de personas flotantes, los niños de la calle que pude conocer en un corto acercamiento de inicio del proyecto de investigación: "Ejercicio de la ciudadanía en el cuidado de la salud de los (as) niños (as) y adolescentes abandonados para obtener calidad de vida". El proyecto analiza la salud, la calidad de vida, y a esa persona llamada niño (a). La teoría dice que salud es una producción social cuyo propósito fun- damental es el desarrollo humano. Son las oportunidades del individuo o de la colectividad para desarrollar sus potencialidades ( OPS, 1998). Calidad de vida son los aspectos subjetivos u objetivos de la vida cotidiana que contribuyen a promover el bienestar del ser humano (ZHAN, 1992). $\mathrm{Y}$ la persona un ser humano con deberes y derechos claramente ejecutados de acuerdo a su cultura (Costa Rica, 1998).

En una ponencia, la Lic Montejo (1993) refiriéndose a los derechos de los niños (as) menciona como ha ido cambiando la perspectiva de que se les "llame a los jóvenes para ser escuchados" y no para que "escuchen ellos a los adultos". También comenta como la reducción del presupuesto para las instituciones afecta los programas, los empleos y la influencia de ello en la estructura familiar. Esto provoca menos atención de los niños en su desarrollo escolar y una inmigración "hacia la calle" y la sobrevivencia en ella. Se profundiza el hambre de alimento y de afecto. Las expectativas de un mejor empleo dado por una educación esmerada dejaron de ser ciertas. Aunado a la falta de respuesta gubernamental para este problema está el nuevo problema de los niños de la calle. Es la sociedad civil la que debe retomarlos y proponer soluciones.

La Lic Espinoza (1993) comenta la participación en áreas de intervención y prevención del Patronato Nacional de la Infancia (PANI) cuya cobertura abarca menores institucionalizados para trabajar la función de la familia sin reforzar la estructura formal de su núcleo familiar.

Un artículo publicado en la sección "Diálogo" de la revista "Área Chica" Rey de Castro (1993) comenta los derechos vistos por los niños de la calle. Ellos hablan de la vida, la calle, la familia, los derechos del niño y del adolescente. La vida es vender para comer, defenderse de los robos, limpiar carros, cantar. Cuando son internados en refugios son maltratados, lo bueno es que se aprende un oficio. A veces las jóvenes se mandan a la calle por embarazo, o se escapan por maltratos. La calle para las mujeres es más difícil, si la policía las agarra las quieren manosear antes de soltarlas de nuevo. A los niños los explotan cuando les dan trabajo. Las niñas para no robar venden droga y al consumirla se sienten bien. La familia a veces es un desorden, hay adulterio, agresión o envían a 
los hijos a vender a la calle. Los derechos que ellos quieren tener es una casa para vivir, que comer y estudio, poder hablar y ser escuchados sin ser golpeados, ser respetados, libres, poder salir de la casa con un tutor, no con guardias en albergues. Policía respetuosa, no agresora.

Lo que la persona (niño-a) no posee es salud, calidad de vida y menos su derecho como persona. La experiencia nos demuestra que los preconceptos (teoría) que se lleva a la práctica no llegan a las necesidades del sujeto en estudio, su ambiente, su estilo de vida. ( $\mathrm{Su}$ intención es buena pero las estrategias no son las adecuadas) Veamos:

\section{OBJETIVO}

Identificar las condiciones de vida de los niños (as) y adolescentes de / o en la calle y su experiencia de salud.

\section{EXPLORANDO EL CAMINO}

Por medio de notas de campo y con el método de incidente crítico. FLANAGAN (1973) define el incidente crítico como "cualquier actividad humana observable que sea lo suficientemente compleja en sí misma que permita inferencias y previsiones sobre la persona que ejecuta una acción". El incidente crítico fue enfocado partiendo de la pregunta: cuáles son tus actividades diarias?

Procuré entrar en el mundo de los niños, pero quiénes eran esas personas flotantes?, dónde estaban?, por qué?, qué querían?, qué sentían?, cómo se relacionaban?

\section{LO VIVIDO}

Según el artículo "El nuevo cristal con que se mira" (Blitzer, 1993, p 61) se entiende a la niñez como una construcción social y por lo tanto afectada por las variaciones culturales entre sociedades y dentro mismo de una sociedad particular. Conectado a ello, el reconocimiento de las diferencias de clase, sexo, o etnicidad además de las percepciones culturales que afectan el ser niño y desde luego restringen la universalidad del concepto. El nuevo paradigma percibe a los niños como personas en su propio derecho.

Salvaje o ser humano? Para algunos, el niño de la calle es un ser no domesticado, un descastado que amenaza el advenimiento del caos social, un niño lobo. Dada su apariencia descuidada y su frecuente participación en actividades ilegales, estos niños suelen ser percibidos por las autoridades como carentes de moral, de valores sociales y como retrasados mentales (Blitzer, 1993, p 63). El término "niño de la calle" se creó para dar nombre a un fenómeno que la sociedad consideró anormal, incómodo y peligroso para sí misma. Los niños de la calle no se comportan como niños pues son independientes, autónomos, parecen sobrevivir fuera de la esfera de cuidado de la familia y la escuela. No sólo carecen de la inocencia infantil sino que también poseen una sagacidad y conocimiento de estrategias de sobrevivencia inapropiados a su edad. A pesar de su tamaño, estos seres se comportan como adultos, pero en sus conductas más indeseables.

Esas personas eran niños (as) entre 11 y 16 ó 17 años que conocí por medio del "equipo de calle" de un proyecto del Patronato Nacional de la Infancia y que me permitió acompañarlos para que mi acercamiento con ellos fuese más fácil.

En la primera entrevista con los trabajadores del PANI me encontré en la salita de recepción con un niño de más o menos $1,20 \mathrm{~cm}$ de estatura, regordete, con cabello ligeramente crespo, corto sin peinar, orejas coloradas por estar recostado en el suelo de medio lado, ojos chinos, vestía unas tenis sucias sin medias, ropa limpia. Estaba llorando porque los de las "brigadas" no se lo habían llevado. Hablaba bastante pero con angustia, parecía temeroso de perder algo por no haber sido responsable. No se le dejó entrar a la sala de espera pero ese límite pareció aceptarlo. Me dijo que él era de la "calle", oriundo de San Isidro del General y que después de cierto tiempo lo iban a mandar al Albergue de San Isidro en el Sur, cosa que lo horrorizaba. Intuí por lo que expresaba que si era obediente no lo mandaban para el sur que era lo que temía. Decía conocer la vivencia gracias a los que habían escapado de ese lugar. Hablaba con angustia de esto. No conseguí entender claramente a que se refería. De noche duerme en unos cartones en las afueras de las oficinas del Patronato. Uno de los Trabajadores Sociales del equipo de Atención Inmediata llamó al Albergue, luego le dijo que se fuera corriendo para que alcanzara a los demás y salió desesperado.

Una semana más tarde en la primera salida con la Brigada para ir a recoger basura, volví a encontrarlo pero estaba muy agresivo defendiéndo- 
se con temor, con desesperación de otros niños del grupo incluso buscando objetos como una piedra para defenderse de los compañeros. Estaba sumamente alterado, solo. Yo me sentí impotente, incapaz de manejar la situación, con unos deseos de protegerlo, acariñarlo, pero el responsable de la brigada me dijo que no debía intervenir, que debía dejar que se defendiera, que aprendiera a sobrevivir solo porque en las noches yo no lo iba a poder cuidar.

Tres semanas más tarde otra colega me informó que había sido internado en el Hospital Psiquiátrico porque se descompensó con deseos de autoeliminación. Se discutió el caso con el médico para no drogarlo e investigar que hay en la relación con su padre que lo aterroriza. El fenómeno de los niños de la calle ha recibido atención atomizada por instituciones que lo atienden como un apostolado, pero que son paliativos en una sociedad que va en crecimiento demográfico y decrecimiento económico, ambiental. Las oportunidades de vencer la violencia o las experiencias de agresión no se dan, termina en un asilo para "enfermos mentales" en lugar de ser reintegrado saludablemente a la familia o a la sociedad.

Otro que también conocí fue un niño de 10 años, escapado de su casa desde los ocho años. Llegó a las oficinas de PANI descalzo con las uñas cortas pero sucias, con la planta del pie sucia, ropa grande pero limpia, de color moreno, bonito, dientes blancos. Agresivo buscando a su abogada, me dijo con fiereza que él era de la "calle". Comenzó a hacer un recuento de los lugares que conocía: Limón, Puntarenas, Jacob, calle 12, la Coca Cola y otros. Me preguntó si era mío el niño que estaba en la salita de espera. Las zonas de tugurio de donde provienen algunos de estos niños son nido de agresión, violencia marcada por descuido, incompresión, falta de diálogo y es donde sobrevive el más fuerte que se mantiene a la defensiva.

En la siguiente semana fui con el equipo de calle a la brigada. Las experiencias con los niños (as) que asistían a las brigadas fue fácil por el apoyo de los organizadores de la unidad de atención inmediata del Patronato Nacional de la Infancia, pero difícil por el lenguaje y la conducta de los jóvenes que me desorientaban en el contexto cotidiano. El tiempo en esta actividad fue corto porque se suspendieron debido a los actos delicti- vos de los jóvenes en el barrio en el fin de semana. Veamos, el día se inició en el Albergue con el baño de los que llegan "de la calle", población variable de acuerdo a la disponibilidad de los que quieren ir y que se aparecen para formar el grupo.

Hagamos un paréntesis, como dice Blitzer (1993, p 64) una forma de resolver la conducta de estos niños es sacarlos de la calle, haciéndolos invisibles a los ojos del público. El propósito es disciplinarlos de tal forma de reprogramarlos como niños, como continentes suspuestamente vacíos, desvalidos y obedientes, negando sus experiencias pasadas y conocimientos adquiridos. Sin embargo, los niños comienzan un ciclo de entradas a estas instituciones, fugas, delitos recurrente, repetidas aprehensiones por la policía para encontrarse tiempo después en una nueva institución. Las intenciones de estas instiuciones son buenas pero sus recursos escasos para mostrar resultados positivos a mediano y largo plazo que permitan demostrar su efectividad.

En el albergue me encontré los niños que había conocido previamente. El desayuno se sirvió en el Parque Nacional, lo devoraron. Luego, mientras esperábamos el vehículo el grupo comenzó a explorar el terreno con mi persona. Sus frases eran incomprensibles para mí tenían un segundo sentido. Una niña comentó que ella quería un cigarro pues también quería sufrir de cáncer de pulmón. Creíble o no, era desconcertante aceptar que ese mundo yo no lo podía controlar, me angustió. Solo las miradas tranquilizadoras de los colegas del PANI hacían que yo no saliese espantada de ahí.

Me hizo recordar un comentario de Rodríguez (1999, p 9) sobre el libro de Delfina Collado "Canto para no llorar" que habla de ciento veinticinco mil niños que tienen que trabajar en nuestro país para llevar sustento a sus hogares, para vivir entre cartones, para adquirir drogas.

Por fin llegó el vehículo y comenzó otra odisea pues una llanta no estaba bien, por lo que fue necesario ir a la bomba de gasolina con todos los niños. La historia indicó otra faceta cuando los que estaban en la gasolinera comenzaron a irse del lado del carro del PANI por miedo a los jóvenes. Y mientras esperábamos conocí la dinámica de las relaciones entre ellos, habían tres líderes por lo que se peleaban en segundos por cualquier cosa. Por fin terminó asustándose y yéndose uno de los 
niños porque el líder le dijo que ese día debía darle "7000 rojos" (siete mil colones) a las siete de la noche. La agresión fue en aumento mientras esperábamos incluso hasta con un pedazo de bloque y con una cuchilla. El desenlace de ese día no lo pude completar pues tuve que retirarme.

A la siguiente semana los niños estaban de huida, tenían prohibido llegar al albergue porque cometieron actos vandálicos en el vecindario. El fin de muchos de ellos ha sido el Rositer Carballo (centro de reclusión para menores). Para ello podría verse el estudio de Benavides y colaboradores (1993). El personal estaba molesto porque uno de ellos al ser aprehendido mencionó el Albergue como el sitio en que lo conocían y que respondían por él. Quizá para él era la casa de su familia que lo apoyaba y le daba seguridad pero la interpretación del personal fue de mala fama para el Albergue. Debido a la presión del vecindario que juzga por sus prejuicios que "en qué han hecho mal para ser castigados con ese albergue en su barrio". La famosa sociedad con prejuicios, apariencias, indiferencia.

Sin embargo por fuera del albergue estaban dos niños y una niña que reclamaban que ellos no estaban entre esos y que querían entrar a bañarse y a desayunar. La situación fue muy tensa pues al ver que no se les atendía la insistencia iba en aumento y la negativa también por no comportarse adecuadamente. Consecuencia inmediata: reacción contra tres niños que asisten a las brigadas y que estaban reposando plácidamente en el corredor por fuera del Albergue, los mandaron levantar e irse, lo que originó rabia, improperios al sentirse despreciados con hambre, dolidos por no haber sido los culpables de lo sucedido. ¿Qué puedo hacer yo?

Comentando lo sucedido en el Pani, llegué a los siguientes comentarios, la tolerancia es necesaria para aceptarlos con amor, pero el Albergue tiene normas como no aceptarles conductas de masturbación en público, agresiones o sea comportamientos de clase media, sólo, que la clase media no los acepta en su medio. En el Albergue de los niños pequeños existen casos de sarna, piojos, diarrea y no tienen atención adecuada de servicios de salud. El trabajo de las brigadas es paliativo, les da soporte, permite el cambio, da la oportunidad pero después de 8 horas al día los deja en las calles bajo la lluvia sin comida. Físicamente son muy sanos, socialmente, emocionalmente no tiene represión para manifestarse, expresarse. Son más sanos menos complicados para sus relaciones sociales, más auténticos porque dicen que van a robar a fulano de tal y lo hacen para demostrarlo. Realmente desestructuran. El personal de la unidad de Atención Inmediata vive tenso, con gastritis, colitis por tanto trabajo desgastante, con casos difíciles de agresión y sin resultados a corto plazo.

Por esto la directora del albergue me permitió entonces permanecer allí. En el albergue pude realizar entrevistas informales con los niños (as), tuve una grata experiencia con uno de los jóvenes que quería su traslado al albergue en San Vito de Java. Fue bastante elocuente en sus apreciaciones sobre la salud, la calidad de vida y la ciudadanía. Tenía 17 años, de cabello largo crespo con una cicatriz en la cara de puñal en medio de los lóbulos frontales, moreno, con un anillo en la mano derecha, dientes blancos y parejos. Limpio con uñas cortas y limpias (las de las manos), las de los pies no sé. Con herida en el dorso de la mano derecha cerrada por segunda intención con tejido de cicatrización. Parece ser de una mordida de un perro alemán. Le fueron suturadas las otras y se le colocó un toxoide hace más de un mes.

Es un joven de hablar fluido, afable, extrovertido. Mi primer acercamiento fue cuando manifestó que quería llamar a San Vito de Java, albergue que ayuda a los jóvenes a aprender un oficio. Luego estaba radiante porque fue aceptado. Tuvimos una plática como de una hora sobre diversos temas.

Me comentó como desde los 9 años "se tiró a la calle", sus tres hermanos mayores no lo hicieron solo él y la hermana que le sigue. Estuvieron en Limón, Puntarenas, Guanacaste. Él ha estado internado en el Luis Felipe González Flores (centro de reclusión de menores) por robar. Ha fumado marihuana, inhalado cemento, kraft. Con el cemento dice que aunque sea "golpeado" (drogado) no se siente, apenas se deja de inhalar hace conciencia de lo que pasa a su alrededor. Con el kraft le dan dolores cuando lo golpean, siente un temblor en las manos y miedo ante quienes lo agreden. Se inhala en los bunkers (lugar de distribución de droga y donde se drogan en comunidad) pero deben conseguir hasta $\# 5000$ pesos por día para poder adquirirlo con la salvedad de que pueden dormir la noche 
ahí. En una ocasión estando con su hermana inhalándolo le propuso que dejaran la droga y ella no le hizo caso.

Cuando ha estado con gripe se ha curado por sí solo porque no tiene ni una pastilla para tomar y cuando ha tenido diarrea, se acuesta se duerme y deja que pase. Ha conocido el lado bueno y el lado malo de la vida. Ha tenido miles de padrastros. Para él el lado bueno es darse bien con la gente, que le tengan confianza, que lo respeten, trabajar honestamente, comer bien. El lado malo es que lo agredan, lo echen de todo lado, lo menosprecien. Él huyó de la casa porque su madre le decía que tenía ropa, comida y lugar para dormir y que él no daba nada, (rol de los niños en la economía familiar), (Blitzer, 1993, p 60). Creyó que en la calle era menos humillado, agredido y fue peor. En el reformatorio tenía que conocerse, aprender a vivir entre ellos ya que viven haciendo "bronca" por todo, había que pelear mucho para defenderse. Para robar necesitaba un cuchillo para que las personas le dieran lo que les pedía y no se le fueran encima. Tuvo una novia tres años menor que él que lo estimulaba a dejar la droga, pero cuando él estaba bien se "apretaba" (abrazaba) con otros y él volvía a la droga. Desde el 20 de 0ctubre lloró mucho en un parque, le pidió a Dios que lo sacara de este tipo de vida. En el albergue le dicen que no recuerde el pasado, pero él sabe que acordándose de los malos ratos no va a volver a caer porque no quiere volver a pasar lo que ha vivido. En cambio si se olvida puede volver a lo mismo. Habla de Dios como su protector desde que lo empezó a conocer con personas del programa del Ministerio del Amor que funciona en Higuito de Desamparados y de un Millón de Amigos que funciona por Plaza González Víquez.

Habló sobre lo que el Albergue les proporcionaba y sobre lo que no daba como pasta de dientes, cepillo, champo, desodorante. Él tenía algunas cosas porque se "pellizcaba" y las había conseguido. Piensa salir de ese mundo de la calle por sí solo y no por otros medios como una novia.

La actividad de recreación dominical fue otro tipo de experiencia, la aceptación fue mejor porque giraba en torno a los pro y contra del encuentro de fútbol, experiencia gratificante y de respiro en medio de tantos vaivenes en la vida de los jóvenes. Me encontré al colega del Pani, repar- tiendo la ropa del "atlético La Barra" y haciendo la lista de los que iban a participar en el juego. Los niños no tenían tacos ni tenis para el papi fútbol, solo tenis corrientes que se repartían, zapatos de la escuela o sandalias para jugar. Las camisas eran muy ajustadas para jugar. El juego era en el gimnasio del colegio Salesiano en Zapote.

La población estaba constituida por los niños de Tirrases que trabajan como "buzos" (seleccionando y recogiendo basura) en el Basurero de Río Azul, en las intersecciones vendiendo o pidiendo para mantener sus familias, en el mercado jalando frutas y verduras o en el Hotel Corobicí y en el Supermercado Tikal jalando los carros de comida. (Ver estudio de Amador y González, 1993). Pero también estaba la niñez de la calle. Algunos de ellos, adolescentes con marcada xifosis probablemente por el tipo de trabajo, no comprendieron lo que les explique de las malas posturas y sus consecuencias en la salud. Había otro con labio leporino y agenesia de unos dedos de la mano derecha, no aceptó hablar sobre el tema, parecía cohibido. Fue maravilloso verlos como jugaban con una energía que hasta sudaban copiosamente pero no tenían agua para tomar ni un baño en condiciones para después del partido. Las otras colegas del Pani trajeron para el almuerzo solo arroz con frijoles que fue devorado sin un refresco para acompañar.

Al siguiente domingo fue en Barrio Cuba, satisfactorio, legal, de camaradería y sobre todo de felicidad por los refrescos y las galletas al final del encuentro. $\mathrm{Y}$ así sucesivamente por varios domingos, la población cambiaba constantemente, solo unos pocos eran perseverantes, labor del colega que los motivaba en la semana. Una experiencia agradable y frustrante a la vez fue en el colegio Calasanz cuando se formaron dos equipos de niños que atender y mi colega me pidió que me hiciera cargo de los más jóvenes. La frustración fue cuando no acertaron un penal porque según ellos por mi ignorancia en el fútbol no escogí al mejor para la jugada. Estaban bien bravos porque no ganaban y el caer continuamente en el barro los tenía sin cuidado. Era cansado pero alentadora la camaradería al compartir los juegos. Es otra faceta que demuestra que son los mismos niños de cualquier clase social cuando se trata de recreación y esparcimiento, solo que sin apoyo de su familia y con más habilidad para enfrentarse a los retos y a la lucha. 
La recreación es un derecho de los niños (as) aceptada como norma social o como tratamiento en el caso de los niños institucionalizados en el Rositer Carballo (Benavides y colaboradores, 1993, p 31).

\section{INSTITUCIONES ALTERNATIVAS}

Programas con un nuevo enfoque, preocupados por dar voz al conocimiento acumulado para fines positivos, sin reproches ni juicios de valor; que reconocen al niño como individuo con experiencias, habilidades y conocimientos. Algunas de las que pude identificar más de cerca por medio de los niños fueron: Hogar Madre de Dios (Pastoral Social del niño) en Barrio Cristo Rey; Ministerio de Amor en la calle (PRENNC); Ejército de Salvación; Casa Alianza; los Salesianos; Oratorio Don Bosco Sor María Romero; PANI = Centro de Integración Diurna y Capacitación.

\section{REFLEXIÓN CRIITICA \\ DE LA EXPERIENCIA}

- El trabajo con la población generó mucha tensión por varias razones:

1. Desconocimiento de las condiciones ambientales, culturales de la población para una comunicación sana con las personas sujetos de estudio y plantearse soluciones apropiadas.

2. Falta de objetivos específicos para organizar el trabajo con los niños (as).

3. Política poco clara con relación a la meta que se pretendía lograr, por consiguiente falta de sustentabilidad (calidad) y sostenibilidad (planificación estratégica a largo plazo) en los programas ejecutados.

4. Personal flotante, poco estimulado, estresado por falta de un horizonte pertinente en cuanto al trabajo a largo plazo con la población infantil de y en la calle y a sus garantías y beneficios individuales, perjuicio para el arraigo en el trabajo.

5. Sometimiento a organizaciones filantrópicas con objetivos específicos que rivalizaban en algunos aspectos culturales con la población y la institución estatal.

6. Falta de interdisciplinariedad gubernamental para hacer un frente común a la proliferación y desarrollo de la población infantil de y en la calle.

\section{LECCIONES APRENDIDAS}

Las áreas centrales en donde se lograron avances importantes en cuanto a la producción del conocimiento: Investigación en enfermería; la imagen que tiene la población de que enfermería sólo sirve para realizar técnicas, se desconoce cuál es su objeto de estudio y su método de trabajo.

No se puede abrir un campo nuevo de trabajo sino se cuenta con una experiencia previa obtenida por la observación participante, las notas de campo, una reflexión crítica sobre los caminos correctos a seguir para los posibles productos que se pretenden obtener. Las soluciones planteadas deben ser participativas, por tanto con intervención de la comunidad, familias, instituciones y de las diferentes disciplinas. El camino más acertado sería el de reintegrarlos a la familia, mejorar su ambiente, condiciones de vida, autoestima al enseñarles que son personas con derecho a participar en su desarrollo. Iniciar el trabajo en los focos de producción de esa población "de y en la calle". No sacarlos de sus medios y de sus estrategias de sobrevivencia, al contrario se les reintegra a sus familias y comunidades y de lo contrario se los incorpora a centros donde se busca recrear una atmósfera de solidaridad familiar, pero en los que cada miembro es responsable por sus propias acciones. Establecer una política gubernamental multisectorial, multidisciplinaria que aborde el problema infantil desde la raíz, con la familia y con la comunidad. Indicar objetivos, metas y métodos específicos multidisciplinarios para realizar investigación acción e impulsar el desarrollo humano de las poblaciones en riesgo.

\section{CONCLUSIONES}

Se identificó que sin la socialización de una familia, sin una definición clara o concreta sobre salud, calidad de vida, libertad de decidir su cuidado de salud, sin un concepto claro de persona, tienen sin embargo una identidad propia, una forma de defender sus derechos, de tener salud, calidad de vida.

Conviven con un concepto de persona que construyen desde su realidad, de defenderse, no dejarse de nadie, que discuten, son tratados como inadaptados pero en realidad ellos ejercen su ciudadanía a su manera. Son personas que no tienen 
que comer, no poseen su propio guardarropa, ni una educación que les permita conseguir un empleo para vencer o enfrentar la pobreza. Por eso tal vez la deserción del sistema educativo, el subempleo los hace terminar más pobres en medio de violencia, agresión, drogas o criminalidad.

Tienen autosuficiencia, autonomía en el cuidado de su salud, son ellos por ellos mismos. Las perspectivas para desarrollar sus potencialidades no son quizá las que la cultura considera saludables. Lo que hace falta es un programa para movilizar conciencia sobre las mejoras en su calidad de vida, bienestar que puede ser dado por la resiliencia y que se debe cultivar.

La experiencia de salud con los niños (as) y adolescentes de/ o en la calle en sus condiciones de vida es un área inexplorada para enfermería por lo menos en Costa Rica.

\section{BIBLIOGRAFÍA}

AMADOR, R; GONZÁLEZ, L. (1993) Características' de las familias y de los niños trabajadores de la calle. Revista de Ciencias Sociales 59, 19-26, marzo.

BENAVIDES, T; GONZÁlez, D; MOLINA, C. (1993) El menor deambulante en Costa Rica. Revista de Ciencias Sociales 59, 27-35, marzo.

BLITZER, S. (1993) Según el cristal con que se mira. Definiciones de niñez y su aplicación al niño de la calle. Boletín medio ambiente y urbanización. Vol 11, n 45. Diciembre. p p 259-66.
COSTA RICA. Código de la niñez y la adolescencia. Asamblea Legislativa: Ley n 7739, Gaceta, 6 de febrero de 1998.

ESPINOZA, M. (1993) La problemática de la niñez costarricense y las acciones gubernamentales en este ámbito. Memoria: I Encuentro Nacional de la Juventud contra el hambre de los niños. San José: Ministerio de Cultura, Juventud y Deportes. Noviembre.

FLANAGAN, J.C. (1973) A técnica do incidente crítico. Arq. Bras. Psicol. Apl., v 25, n 2, p 99141.

GARCIA-PELAYO y GROSS, R. (1976) Pequeño Larousse en color. Canadá: Larousse.

MONTEJO, A. (1993) Problemática de la niñez en el marco de la conferencia de los derechos de los niños y de las niñas. Memoria: I Encuentro Nacional de la Juventud contra el hambre de los niños. San José: Ministerio de Cultura, Juventud y Deportes. Noviembre.

O P S. (1998) Salud en las Américas. Washington: OPS.

REY de CASTRO, J. (1993) Cuatro niños conversan. Los derechos vistos por los niños de la calle. Revista: Área chica. Vol 3, n 26/27. Agosto/ setiembre.

RODRÍGUEZ, C. El desgarrador relato de nuestros niños. Eco católico. 28 de marzo de 1999. p. 9.

ZHAN, L. (1992) Quality of life: conceptual and measurement issues. J. Adv. Nurs., v 17, n 7, p 795800 . 